\title{
Gérard Piacentini, Samuel Beckett mis à nu par ses auteurs, même. Essai sur le Théâtre de Samuel Beckett
}

\section{Emanuele Kanceff}

\section{(2) OpenEdition}

12 Journals

\section{Edizione digitale}

URL: http://journals.openedition.org/studifrancesi/9667

DOI: 10.4000/studifrancesi.9667

ISSN: 2421-5856

\section{Editore}

Rosenberg \& Sellier

\section{Edizione cartacea}

Data di pubblicazione: 1 décembre 2007

Paginazione: 696

ISSN: 0039-2944

\section{Notizia bibliografica digitale}

Emanuele Kanceff, «Gérard Piacentini, Samuel Beckett mis à nu par ses auteurs, même. Essai sur le Théâtre de Samuel Beckett», Studi Francesi [Online], 153 (LI | III) | 2007, online dal 30 novembre 2015, consultato il 10 janvier 2021. URL: http://journals.openedition.org/studifrancesi/9667 ; DOI: https:// doi.org/10.4000/studifrancesi.9667

Questo documento è stato generato automaticamente il 10 janvier 2021.

\section{(c)}

Studi Francesi è distribuita con Licenza Creative Commons Attribuzione - Non commerciale - Non opere derivate 4.0 Internazionale. 
Gérard Piacentini, Samuel Beckett mis à nu par ses auteurs, même. Essai sur le Théâtre de Samuel Beckett

Emanuele Kanceff 


\section{NOTIZIA}

GÉRARD PIACENTINI, Samuel Beckett mis à nu par ses auteurs, même. Essai sur le Théâtre de Samuel Beckett, Préface d'Armand DELCAMPE, Saint-Genoup, Librairie Nizet, 2006, pp. 158.

1 Mi pare si possa dire che Gérard Piacentini ha il teatro nel sangue. E così, anche il suo libro è costruito come una rappresentazione, dall'ingresso in sala del pubblico alla calata del sipario. L'autore riprende qui studi che aveva iniziato fin dagli anni Settanta del secolo scorso, nella sua tesi di dottorato, La vision tragique dans les premières pièces d'Eugène Ionesco (1978) e nel suo libro Adamov, Beckett, Ionesco, néoostoïcisme et tragique dans le théâtre des années '50 (1987), nel reiterato tentativo di offrire una visione nuova dei massimi autori drammatici di metà Novecento. Beckett, in particolare, gli appare privo di ambiguità, autore tra i più precisi e di più chiara interpretazione. In En attendant Godot e in Fin de partie, secondo l'interpretazione che ce ne offre Piacentini, Beckett ha scritto la fine di un'epoca, ha illustrato la metafora del declino del pensiero e dell'arte francese negli ultimi due secoli, come nessuno aveva mai avuto il coraggio di esprimere prima di lui. Proseguendo negli approfondimenti di una particolare lettura dei testi, Piacentini rivela l'importanza del tema del Maestro e del discepolo, che ritiene essenziale nel teatro francese moderno. La sua indagine si rivolge, successivamente, al modo che Beckett presenta nella sua opera, alla tecnica che lo scrittore mette in opera, alla scelta biografica, rappresentata da Oh, les beaux jours. Questo drammaturgo che ha fatto di tutto per imbrogliare le carte e mettere i critici fuori pista ha realizzato, in effetti, un'impresa unica: dire il proprio mondo con le parole altrui. 